\title{
A heresia política dos monges barbudos no período de consolidação do Estado Novo: fontes, historiografia, contexto
}

The heresy of bearded monks in the policy period of consolidation of the New State: sources, historiography, context

Fabian Filatow* fabianfilatow@gmail.com

Resumo: O movimento dos Monges Barbudos ocorreu entre 1935 e 1938, em Soledade (RS). Sua origem está associada com a figura do monge João Maria, o qual teria estado na localidade e instruído uma nova religião. Reunindo um significativo número de membros o movimento despertou a atenção da comunidade local e das autoridades que recorreram ao uso da força militar para reprimi-los. O conflito ocorreu durante o ano de 1938, quando o grupo composto por camponeses se reuniu na capela de Santa Catarina a espera do retorno do santo monge. A repressão deixou um saldo de mortos e feridos, além do medo e da proibição da prática religiosa. Inseridos num contexto político complexo foram acusados de serem comunistas. Esse fato contribuiu para legitimar a ação repressiva orquestrada pelo Estado. Após cinquenta anos de silêncio foram publicadas as primeiras obras sobre o ocorrido. Nestas o aspecto religioso foi privilegiado. Nosso estudo busca apresentar a relação entre o contexto político regional e nacional com a prática da violência que foi promovida contra o movimento. Para isto, utilizamo-nos de um variado leque documental. Enfim, os Monges Barbudos foram reprimidos pelo contexto no qual estavam inseridos. Foram, assim, utilizados politicamente para dar estabilidade ao novo regime recéminstaurado em 10 de novembro de 1937.

Palavras-chave: monges barbudos, processos crimes, história política

Abstract: The movement of the Bearded Monks took place between 1935 and 1938, in Soledade (Rio Grande do Sul). Your origin is associated with the figure of the monk João Maria, which would have been in the locality and instructed a new religion. Bringing together a significant number of members the movement aroused the attention of the local community and of the authorities resorted to the use of military force to repress them. The conflict occurred in 1938, when the group composed of peasants gathered in the chapel of Santa Catarina waiting for the return of the Holy monk. The crackdown left a balance of dead and wounded, besides the fear and the prohibition of religious practice. Inserted in a complex political context have been accused of being Communists. That fact helped to legitimise the repressive action orchestrated by the State. After 50 years of silence were published the first works about it. In these the religious aspect was privileged. Our study seeks to show the relationship between the national and regional political context to the practice of violence that was promoted against the movement. For this, we used so a varied range of documents. Anyway, the Bearded Monks were repressed by the context in which they were inserted. Were used politically to give stability to the newly established regime in new November 101937.

Keywords: bearded monks, criminal cases, political history

*Doutor pela Pontifícia Universidade Católica do Rio Grande do Sul (PUCRS). Professor da rede Estadual de Ensino do Rio Grande do Sul - SEDUC, e da Prefeitura Municipal de Esteio/RS. 


\section{Introdução}

O homem não vive somente a sua vida individual; consciente ou inconscientemente participa também da vida da sua época e dos seus contemporâneos. (MANN, Thomas. A montanha mágica. Rio de Janeiro: Nova Fronteira, 1980, p. 42.)

O regime autoritário do Estado Novo foi implantado no Brasil em 10 de novembro de 1937. Caracterizou-se pelo fortalecimento do centralismo frente ao federalismo, realizando o desmantelamento do poder das oligarquias regionais. Muitos aspectos desse período já foram objetos de estudos. Nosso foco está em analisar a repressão efetuada pelo Estado contra um grupo religioso composto por camponeses localizados em Soledade, interior do Rio Grande do Sul. Este movimento foi acusado de ser comunista, fato que foi amplamente divulgado, explorado e que, de certo modo, contribuiu para a ação violenta imposta por tropas da Brigada Militar em abril de 1938.

O movimento dos Monges Barbudos, como ficou conhecido, não foi uma exceção nesse período. No interior da Bahia outro grupo religioso nomeado Pau de Colher também foi alvo da repressão imposta pelo Estado Novo. Também a acusação de serem comunistas esteve presente. Além desta semelhança, podemos identificar que em ambos os estados - RS e BA - seus respectivos governadores se opuseram ao golpe de novembro de 1937. Ambos foram destituídos de seus cargos, sendo substituídos por interventores.

Neste estudo nos dedicaremos a apresentar a construção da ameaça comunista associada aos camponeses de Soledade, região que foi reduto do Partido Republicano Liberal (PRL), ligado a Flores da Cunha de 1932 até 1937. O partido ofereceu sustentação política tanto a Flores como a Vargas neste período. Acreditamos que a repressão efetuada em Soledade foi uma ação política, visto pairar dúvidas de que o movimento dos Barbudos fossem homens de Flores da Cunha, ou adeptos do flo- rismo, após seu afastamento do governo gaúcho. Ambas as acusações não foram confirmadas - comunistas e floristas - nas incursões e averiguações efetuadas pelas forças policiais, porém a repressão foi efetuada assim mesmo, sob a legalidade da lei de Segurança Nacional.

A historiografia referente aos Monges Barbudos é escassa, porém podemos distinguir dois tipos de produção. O primeiro é composto por obras que estudaram o movimento em si, buscando compreender sua religiosidade, sua cultura, o sagrado (PEREIRA, WAGNER, 1981; KUJAWA, 2001; FILATOW, 2002; CREMONESE, 2004; KOPP 2014). Um segundo grupo pode ser identificado por obras que buscaram estudar a história de Soledade e que inseriram a ocorrência do movimento como um fato religioso excluído do processo político vivenciado naquele momento (FRANCO, 1975; VERDI, 1987; WEDY, 1996; GUERREIRO, 2005). Nossa proposta foi realizar uma leitura política do caso dos Monges Barbudos. Com isso não afirmamos que eles tenham se identificado com alguma das correntes políticas ou partidárias então vigentes. Buscamos, sim, analisar o uso do movimento para fins políticos, quando estes foram acusados de comunistas ou aliados ao florismo, sendo apontados como uma possível ameaça à ordem nacional, o que naquele período legitimaria ação enérgica.

Assim sendo, num primeiro momento apresentaremos o contexto político de Soledade e o surgimento do movimento dos Monges Barbudos. Num segundo momento, apresentaremos a acusação política, a ameaça comunista presente em diferentes fontes. Metodologicamente utilizamos a análise de conteúdo para ordenar o mosaico documental.

\section{Breve contexto político de Soledade}

Soledade sempre se configurou num cenário político conflitante, tanto no âmbito local quanto re- 
gional. Em 1930 esteve na Aliança Liberal que levou Vargas ao poder do Brasil. Porém, discordando dos rumos e das promessas não cumpridas apoiou a causa constitucionalista de 1932, chegando ao conflito político-militar conhecido como Combate do Fão, onde soldados leais ao interventor federal e ao Governo Provisório enfrentaram os rebelados de Soledade, sob a liderança de Cândido Carneiro Júnior. O conflito abriu caminho para uma forte retaliação política no município. O PRL assumiu o controle municipal. As desavenças políticas perduraram mesmo com o fim do combate armado. Violência, incluindo assassinatos, marcou os anos subsequentes de Soledade. Em 1934, ocorreram eleições, novamente o clima ficou extremado e novas práticas de violência política foram noticiadas pela imprensa. Por fim, ocorreu o surgimento dos Monges Barbudos em 1935, atingindo seu ápice em 1938. Sua existência foi concomitante ao período de afastamento político entre o então governador Flores da Cunha e Getúlio Vargas. Desavenças políticas que culminaram com a deposição do governador gaúcho e seu exílio no Uruguai e a instauração do golpe do Estado Novo, tendo Vargas permanecido à frente do poder executivo nacional.

\section{O movimento dos Monges Barbudos}

Era novembro de 1935 quando um santo monge teria estado no município de Soledade (RS) e pernoitado na casa de André Ferreira França, conhecido como Deca França. Deste encontro teria nascido o movimento religioso. Pelo menos é o que nos legaram os relatos sobre a gênese dos Monges Barbudos. Segundo Valdemar Cirilo Verdi,

Um andarilho pernoitou na casa de André Ferreira França. Em troca da hospitalidade, o andarilho ensinou-lhe a arte e o segredo das ervas medicinais. Ter-lheia também ensinado outras utilidades da natureza, chamando a atenção para a nobreza do sol, dos rios, da lua, das ma- tas... Alertou sobre os males do fumo plantado por colonos e guardado dentro de casa para secar. Tendo permanecido breve temporada, ao final das lições e ensinamentos, o andarilho apresentou-se como João Maria, ou o santo monge João Maria, [...], assegurou que Deca França havia sido escolhido para uma missão divina. Deveria escolher uns amigos para fundar uma seita de eleitos. (VERDI, 1987, p. 93).

André Ferreira França teria vindo de Cachoeira do Sul para Soledade volta de 1894 e se estabelecido no local conhecido como Campestre. Seria analfabeto e pertenceria a uma família de algumas posses, porém teria renunciado a todos os seus pertences materiais após seu encontro com o santo monge e ter aceitado a incumbência que lhe foi profetizada. Sua residência tornou-se um local de encontros religiosos. As pessoas encontravam-se para rezar e aprender sobre os benefícios das ervas para fins medicinais. Tais conhecimentos teriam sido recebidos diretamente do profeta, como o santo monge ficou conhecido na região. Sobre a formação do movimento, o jornal Kolonie, de Santa Cruz, noticiou:

Já há algum tempo, tem-se ouvido ocasionalmente rumores e notícias mais sérias sobre a aparição de um "santo" ou "monge" na região fronteiriça, especialmente no $6^{\circ}$ distrito do município vizinho de Soledade. Conhecida como uma região em si não muito tranquila, de início os rumores foram menosprezados como boatos vazios, ainda que algumas vozes mais sérias tivessem se elevado, relatando forte movimento de pessoas se bandeando para o lado do fanático. (KOLONIE, Santa Cruz do Sul, 27 ABR 1938, p. 2).

Frederico Ibner, colono alemão e dono de bodega e vizinho de André França, relatou que "não reconhecia mais o vizinho, cujos cabelos e barba cresciam com toda liberdade". Declarou que em pouco tempo "eram muitos os barbudos." Ao apresentar seus motivos para não ingressar na nova religião declarou "não acreditava, primeiro, porque o Deca era um colono igual a 
gente, criado aqui no nosso meio; não ia, de repente, virar santo. Segundo, porque esse pessoal todo, que era gente pobre e sem esperanças na vida, foi engolido pelo fanatismo. Depois eu já tinha minha religião, sou luterano." (COOJORNAL, Porto Alegre, MAIO 1980, p. $30)$.

Não podemos afirmar com certeza os reais motivos que fizeram Deca ser hostilizado, mas o fato é que ele passou a ser indesejado na região, atraindo sobre si o ódio de muitas pessoas da localidade, destacadamente aquelas que não compartilhavam da nova crença. Tiveram início os conflitos entre os membros do movimento religioso e os não adeptos. Deca França passou a ser perseguido e precisou viver escondido, fato que explica sua ausência no encontro profetizado para a semana santa de 1938, na capela de Santa Catarina, localizado no $6^{\mathrm{o}}$ distrito de Soledade, nomeado Bela Vista. Segundo a crença, a data marcaria o retorno do santo monge, fato que levou muitas pessoas a se dirigirem para a localidade. Segundo o jornal Correio do Povo, "um grupo de fanáticos, superior a mil, inclusive mulheres e crianças, invadiu os municípios de Soledade e Sobradinho, apossando-se da igreja Santa Catarina [...]." (CORREIO DO POVO, Porto Alegre, 21 ABR 1938, p. 16). Numa carta enviada de Sobradinho e publicada pelo jornal Kolonie, temos:

Em toda a região fronteiriça entre Sobradinho e Soledade teria havido tumultos. Se os fanáticos haviam se mantido até então escondidos no mato, agora eles haviam surgido de repente em grande número - alguns sustentam que eram até 1000 pessoas, entre homens e mulheres na Praça da Bela Vista no $6^{\circ}$ distrito de Soledade. À população haveriam declarado que chegara o momento de se colocar em contato com Deus, por meio de Santa Catarina, a sua padroeira. (KOLONIE, Santa Cruz do Sul, 27 ABR 1938 , p. 2).
Esta reunião teria alarmado a população local, que com medo, recorreu às forças de segurança exigindo proteção. No dia 14 de abril daquele ano ocorreu o confronte entre os Monges Barbudos e os soldados da Brigada Militar. Durante estes acontecimentos, destacou-se um segundo líder do movimento, Anastácio Desidério Fiúza, conhecido como Tácio Fiúza. Estando à frente dos fieis foi baleado, ferimento que o levou a óbito no dia seguinte, 15 de abril de 1938. (VERDI, 1987, p. 98) Sobre a morte de Tácio Fiúza, temos o relato do capitão Riograndino da Costa e Silva:

Sendo pressentida a aproximação da força, que vinha em um caminhão, alguns elementos que se supõe estivessem armados, fugiram para os matos que circundam a capela, recebendo hostilmente a escolta. Deu isso lugar a que se travasse um ligeiro tiroteio, onde veio a ser ferido Tasso Fiuza, tido como um dos chefes dos fanáticos. Em consequência dos ferimentos recebidos, soube-se, mais tarde, que o mesmo viera a falecer. Na ocasião da chegada da força encontrava-se ele no interior da igreja e, procurando sair pela porta da frente, atirou contra um soldado que estava mais perto dele mas errando o alvo, atingiu duas pessoas do seu próprio grupo. Como tivesse saído em direção ao mato próximo, a escolta o alvejou, ferindo-o e ele veio mais tarde a falecer em consequência dos ferimentos recebidos. (CORREIO DO POVO, Porto Alegre, 27 ABR 1938, p. 14).

Após o trágico confronto André Ferreira França resolveu se entregar, o que foi marcado para ocorrer na casa de um dos membros do movimento, José Crispim, onde Deca esperava a chegada do destacamento policial. Porém, com a chegada da força policial à residência Deca França foi morto a tiros. Seu corpo foi lançado numa cova, a qual permaneceu vigiada por policiais, por se temer que os fieis viessem desenterrá-lo, pois havia a crença de Deca não morreria e, caso isso viesse a acontecer, ressuscitaria. Crença que existia também no caso de Tácio Fiúza, “(...) o corpo de Fiúza foi velado, durante três dias, na persuasão de que o mesmo vi- 
esse a ressuscitar. Como isto não se desse, resolveram enterrá-lo, dizendo que 'ele havia ressuscitado para baixo'." (CORREIO DO POVO, Porto Alegre, 27 ABR 1938, p. 14).

Outra versão sobre o enterro de Tácio foi relatada por Frederico Ibner, o qual era o único morador do Despraiado que não se converteu à seita. Era crença corrente entre os perseguidores que os fanáticos velaram Tácio durante dois dias na esperança de vê-los ressuscitar. Tácio foi velado entre os dias 15 e 16 de abril, na residência de Alípio Costa, na localidade conhecida como Rincão dos Bernabés, que ficava próximo da Vila de Jacuizinho. A versão dos monges declarou que o “cadáver permaneceu dois dias insepulto por causa das chuvas fortes que caíram naquela semana. No dia 16, ao entardecer, decidiram enterrá-lo, como recorda seu filho Arator, hoje com 53 anos, mesmo com aquele aguaceiro todo." (COOJORNAL, Porto Alegre, MAIO 1980, p. 29).

Ainda sobre as crenças do movimento temos que além do retorno do salvador teria sido profetizado o reordenamento, ou seja, os que pertenciam e tinham aceitado os ensinamentos da religião tornar-se-iam donos de todas as coisas na Terra e seriam salvos, destino contrário era esperado para os incrédulos. $\mathrm{Na}$ semana santa de 1938, "espalhou-se o boato de que vinham para aguardar o fim do mundo. [...]. O mundo findaria, mas os monges escapariam e, salvos, herdariam o que sobrasse. Todos virariam santos e ganhariam uma companhia muito especial: Cristo ressuscitado." (COOJORNAL, Porto Alegre, MAIO 1980, p. 29).

Referente à questão do trabalho, não há uma unanimidade. Alguns relatos declaram que os Monges Barbudos não trabalhavam, pois acreditariam que todas as suas necessidades seriam provindas dos céus. Noutros temos que trabalhavam sim, mas produziam so- mente o suficiente para si e para os membros do grupo. Segundo relato de frei Clemente,

[...] os recibos de 1937 e quase todos deste ano, o que põe por terra mais essa acusação. Acoimados de não trabalharem, e fomos encontrar todos, porém, com roças bem plantadas de feijão, trigo, milho etc. Tudo isso demonstra que as acusações atiradas contra os moradores da colônia das Tunas são puras calunias. É proibido também pela religião andar armado de arma de fogo e também de arma branca de excessivas dimensões. Pois os poucos facões que tinham, lhes foram arrebatados pela polícia. Eles nos disseram mesmo que não tinham faca nem para sangrar um porco. (CORREIO DO POVO, Porto Alegre, 23 DEZ 1938, p. 5).

Sobre os Monges Barbudos foi divulgada a ideia de que eram comunistas. Acredito que talvez esta tenha se gerado pelo parco ou nenhum conhecimento sobre o que realmente significava ser comunista, mas devido às propagandas anticomunistas divulgadas naquele período. Somando-se a questão da terra, a qual seria de todos e a diminuição do trabalho podem ter contribuído para complementar a ideia divulgada de serem comunistas.

Temos a informação de que frei Clemente esteve pessoalmente no reduto dos Monges Barbudos, permanecendo uma semana.
Depois, entretanto, das medidas postas em prática no decurso do último inverno, quando se manifestou a existência dos chamados "fanáticos de Soledade", re- solveu o capitão chefe de polícia enviar à localidade onde estava sediado o grupo - $6^{\circ}$ distrito de Soledade - o vigário daque- la paróquia, frei Clemente, acompanha- do de um inspetor da polícia, o sr. Sylvio Ronda, para averiguar "in loco" as ati- vidades dos "fanáticos". Para ali dirigin- do-se, demorou-se aquele sacerdote uma semana, tempo bastante para observar os hábitos, crenças e disposições dos inqui- nados desordeiros. (CORREIO DO PO- VO, Porto Alegre, 23 DEZ 1938, p. 5).

Ao regressar, frei Clemente dirigiu-se à capital do Rio Grande do Sul com o propósito de expor os re- 
sultados da missão. Segundo publicado, "regressando de sua missão, frei Clemente veio a esta capital, avistando-se ontem com o capitão Aurelio Py, chefe de polícia e com o dr. Coelho de Souza, secretário da Educação, expondo a ambos os resultados da visita que fez ao $6^{\circ}$ distrito de Soledade." (CORREIO DO POVO, Porto Alegre, 23 DEZ 1938, p. 5). Em entrevista o frei se referiu às acusações que existiam contra os Monges Barbudos, dentre as quais serem comunistas.

Os monges da colônia das Tunas eram acusados de comunismo, saques, imoralidade, aversão ao trabalho e não pagamento de impostos. Quanto à primeira parte - comunismo - não há vestígio algum que a fundamente. Logo que me apresentei, postos ao par de minha missão, deixaram tudo à minha disposição, sem restrição alguma. Além disso, proclamam obediência absoluta às leis do Brasil e aos princípios gerais da Religião. Dizem que recebiam dinheiro dos comunistas. Eles me responderam que o pouco dinheiro que tinham, fora ganho com o suor do próprio rosto. Trata-se de gente simples e religiosa demais para entrar numa organização diabólica como o comunismo. (CORREIO DO POVO, Porto Alegre, 23 DEZ 1938, p. 5).

Referindo-se às acusações de imoralidades e roubos atribuídos aos Monges Barbudos relatou:

Quanto à acusação de que saqueavam os vizinhos para matarem a fome, não encontramos nenhuma prova. Em reuniões onde estivemos, pudemos observar que quem tinha dinheiro comia, quem não tinha passava fome. Dizia-se também que os monges praticavam imoralidades, especialmente nas danças: segundo se afirmava até certas horas dançavam com luz, depois ficavam às escuras e continuavam dançando. Esta é uma pura calunia, porque a religião deles proíbe a dança; além disso, interroguei o gaiteiro do lugar, que me disse nunca haver assistido a semelhantes cenas, nos poucos bailes em que foi tocar. (CORREIO DO POVO, Porto Alegre, 23 DEZ 1938, p. $5)$.

Após o conflito ocorrido na Capela em Bela Vista várias pessoas foram presas, sendo que "22 monges foram escolhidos como os mais perigosos e envia- dos para Porto Alegre e Cachoeira do Sul." (COOJORNAL, Porto Alegre, MAIO 1980, p. 29). Entre os presos estavam Alfredo dos Santos, conhecido como Ceguinho, Ananias Costa, Alípio Gonçalves, Crescêncio Costa, José Crispim e Adão Alves. Estes retornaram sem demora, porém tiveram cabelos e barbas cortados. A acusação de comunismo ficou invalidada, pois "nada se conseguira provar, a nível político, contra eles." (COOJORNAL, Porto Alegre, MAIO 1980, p. 29-30).

Com a multidão dirigindo-se para a capela de Santa Catarina, os moradores e bodegueiros - donos de pequenas casas de comércio - ficaram temerosos, pois já era conhecida a crença de que "tudo seria de todos", e assim, temeram por suas propriedades e posses. $\mathrm{Na}$ noite de 13 de abril os comerciantes estavam de portas abertas, porém, acabaram os estoques de alimentos. “Como recorda o bodegueiro João Paulo Trevisan, (...), foi quando cresceu este medo que os comerciantes resolveram se unir, pegar nas armas e reagir. Foi ali o começo da violência." (COOJORNAL, Porto Alegre, MAIO 1980, p. 29). Os comerciantes se reuniram na "bodega de Trevisan" e estariam armados com "uma dúzia de revólveres, algumas caixas de balas e com uns 10 homens." Em meio a essa reunião e pânico, teria sido escolhido Oscar, filho do influente Júlio Telles [...] para sair sorrateiramente e buscar a polícia em Sobradinho. (COOJORNAL, Porto Alegre, MAIO 1980, p. 29). A delegacia de polícia de Sobradinho era a mais próxima, a outra seria a da sede municipal de Soledade, muito distante. Sendo o número de policiais insuficiente, foi solicitada a presença de tropas brigadianas de Porto Alegre, Santa Maria e Passo Fundo.

Santa Maria, 20 (C.P.) - A imprensa noticiou que um grupo de fanáticos, superior a mil, inclusive mulheres e crianças invadiu os municípios de Soledade e Sobradinho, apossando-se da igreja Santa Catarina, localizada no $6^{\circ}$ distrito de Soledade, onde se alojou. Os fanáticos 
são chamados "monges barbudos". A polícia entrou em contato com os fanáticos, encontrando resistência, havendo um morto e alguns feridos. Desta cidade seguiu, para normalizar a situação, uma força de quarenta praças do $1^{\circ}$ Regimento da Brigada Militar, comandada pelo tenente Antônio Nunes Pontes. (CORREIO DO POVO, Porto Alegre, 21 ABR 1938, p. 16).

O final deste encontro fatídico ficou redigido no relatório que foi apresentado ao Comandante Geral da Brigada Militar pelo então major José Rodrigues da Silva, sobre os acontecimentos ocorridos no município de Soledade, com o surto de "fanatismo religioso" praticado por elementos que se tornaram conhecidos por Monges Barbudos.

O número de adeptos proporções alarmantes e Tasso [Anastácio Fiúza] determinou uma reunião e marcha para o lugar denominado Bella Vista, onde existe uma igreja de que é padroeira Santa Catarina. Essa reunião efetuou no dia 12 de abril deste ano e a chave da igreja foi obtida mediante ameaças ao encarregado daquele templo. Tendo a população de Bella Vista, alarmada, pedido socorro às autoridades de Sobradinho, o delegado de polícia, Sr. Antônio Pedro Pontes, para lá se dirigiu acompanhado de praças do destacamento daquela cidade. Surpreendidos com a força os fanáticos fizeram alguns disparos de armas curtas e a força também fez uso de suas armas, ferindo o chefe Tasso que veio a falecer logo depois. Foram presos também 10 fanáticos que foram remetidos para $\mathrm{Ca}$ choeira e mais tarde postos em liberdade. Morto Anastácio Fiuza e apesar de batidos em Bella Vista, os fanáticos conduziram o cadáver para o lugar denominado Rincão dos Bernabés," no $5^{\circ}$ Distrito de Soledade e ali o conservaram insepulto durante quatro dias, isto é, até o dia 17 de abril, na estulta crença de que o morto ressuscitasse. Em torno desse prolongado velório reuniram-se para mais de 500 pessoas. De tal reunião e desobediencia as regras da lei foram avisadas as autoridades de Soledade, que fizeram seguir imediatamente para o local uma força do destacamento da Brigada. A força, ao aproximar-se daquele enorme aglomerado de povo, foi recebida com tiros, fazendo também uso de suas armas, resultando a morte do fanático Benjamin
Garcia e ferimento no soldado Oswaldo dos Santos e no fanático Marcolino Alves da Costa. A força efetuou a prisão de 104 fanáticos, entre os quais figurava Maria Candida Ferreira de Camargo, a Santa Catarina. ${ }^{4}$ [sic] (Relatório apresentado ao Comandante Geral da Brigada Militar pelo major José Rodrigues da Silva - Porto Alegre, 12 de julho de 1938)

A presença das santas configura-se em um dado relevante para compreendermos o sagrado dos Monges Barbudos. Eles eram devotos das santas e elas eram veneradas como santas, tendo destaque na vida religiosa dos Barbudos, pois não eram apenas imagens, estavam entre eles, personificadas. Ou seja, Santa Catarina estaria viva na pessoa de Andreza Gonçalves a qual seria sobrinha de Deca França (KUJAWA, 2000, p. 57). Santa Teresinha estaria presente na pessoa de Idarsina da Costa (VERDI, 1987, p. 101-105). Segundo consta, eram ambas jovens e belas, e tinham em 1935, respectivamente, 18 e 15 anos. Elas sofreram perseguições e violências. Ambas foram presas em 1938, recebendo inúmeras humilhações.

Assim como seu surgimento é incerto, envolto por lendas, misticismos e crendices, também seu final está envolvido em muitas lacunas. Acredito que o período no qual o movimento existiu contribuiu para o seu trágico final. Envolvidos nas disputas políticas, onde o anticomunismo e o medo imperaram, ocorreu o uso da violência, mesmo que o relato do major José Rodrigues não tivesse apresentado motivos contundentes para o ato de repressão aos Monges Barbudos.

\section{O santo monge em Soledade}

Manifestações do sagrado também são maneiras pelas quais podemos "ler" as contestações e reivindicações dos membros que compõem um determinado movimento religioso. Pela via religiosa tentam romper com a ordem vigente, vislumbrando outra realidade. Tais contestações encontram-se atreladas à realidade social vivenciada pelos sujeitos que compartilham da 
religião, logo, o movimento religioso está interligado à realidade social, sendo uma forma de expressá-la. Acreditamos ser esse o caso do movimento dos Monges Barbudos.

Nesse sentido, os relatos sobre os milagres atribuídos ao santo monge em Soledade tornam-se relevantes para o nosso estudo, cientes que o personagem foi figura central na origem aos Monges Barbudos. Figura taumatúrgica, considerado santo e fazedor de milagres, pode ser identificada em diferentes localidades do Brasil meridional. Acreditamos ser relevante analisarmos as representações do sagrado, pois estas contribuem para uma melhor compreensão do movimento. Assim, entendemos que representações "são sempre determinadas pelos interesses de grupo que as forjam” (CHARTIER, 1990, p. 17). Assim, iremos compreender as representações do sagrado no âmbito do movimento religioso de Soledade, fazendo-se necessário relacionar o signo visível e o seu referente por ele significado (CHARTIER, 1990, p. 21).

No que se refere à permanência do santo monge em Soledade acreditamos que se deva à contribuição do relato oral. Aceitamos ter ocorrido uma apropriação do nome e das características do personagem, mas entre os fieis, sua existência é real e verdadeira. No município gaúcho, segundo a memória popular, o monge que visitou o fundador da religião dos Barbudos teria sido o mesmo João Maria que peregrinou pelo sul do Brasil. É curioso destacar que nos diferentes movimentos que reivindicam a presença do santo existem fotos semelhantes do personagem.

Contrariando a ideia da unidade do monge, identificamos relatos divergentes sobre a identidade deste personagem em Soledade. Uma é apresentada por João Maria da Silva, que declarou que o monge havia aparecido para seu avô em Santa Maria por ocasião de uma viagem de carreteiros:
Ele [seu avô] já conhecia o monge, dava o nome de São João Maria, Padre Monge e São João Maria de Jesus. Ele se transformava e trocava um pouco o nome. Naquele tempo ele [monge] estava com 180 anos. [...] o monge João Maria se transformava. $O$ senhor podia encontrar ele aqui, e logo ali perguntar para outro se não viu um Monge e receber a resposta: 'não, encontrei uma criancinha desconhecida'. Logo adiante outro responder: 'encontrei uma senhora. (KUJAWA, 2000, p. 50).

Outra versão é encontrada no relatório policial do major da Brigada Militar José da Silva Rodrigues,

Em começo do ano de 1937, o indivíduo de nome André Ferreira França, vulgo Deca, casado, com 56 anos de idade, analfabeto, agricultor e residente no lugar denominado "Campestre" $6^{\circ}$ distrito do municipio de Soledade, iniciou a pregação e prática de crendice Religiosa. André dizia haver recebido ensinamentos de um indivíduo de nome "Antônio de Salles", que se dizia possuidor de faculdades divinizadas pela prática de atos religiosos. Antônio de Salles, segundo fazia constar Deca, trazia consigo uma pequena caixa e um baixeiro de lã. (Major da Brigada Militar José da Silva Rodrigues, Relatório da Brigada Militar ao interventor do Estado, 1938.)

Na primeira temos a realidade de um crente, em cujo mundo religioso é perfeitamente possível a existência desse santo. No relato policial, a versão desacredita o movimento, pois tornando o monge uma pessoa comum, nega o próprio movimento, visto ser a figura do peregrino sua base religiosa.

A imagem de João Maria está sempre associada com a natureza. Destacamos a existência das fontes d'água, que, segundo a crença, foram criadas pelo próprio monge e suas águas teriam poderes curativos, seriam águas milagrosas. Sua presença é mantida viva pela atribuição de caráter sagrado a estes lugares e símbolos. Sebastião Firmino Nunes, morador de Soledade, relatou:

Olha, isto aqui é dos tempos mais agudos, isto é, dos tempos mais antigos, qua- 
se no início do mundo. Meu avô contava muita coisa. Meu pai, que hoje teria 105 anos, contava que o "padre santo" fez nascer a fonte. [...] O monge parou para descansar. Plantou uma cruz de madeira ai mesmo. Olha, tem ainda o sinal. Aqui os demônios perderam ele. Perderam o rastro, como se diz. Quando sentiu sede, não tendo água, levantou a mão e disse: 'Esse lugar é abençoado; dará água para mim tomar; o doente será curado e vai as almas salvar'. Todos que se virem perdidos ou perseguidos se salvam com esta água. Dai estourou a vertente, brotou água pura. (VERDI, 1987, p. 205-206).

Lembrando outro milagre contou o caso de dona Elísia Pereira que sofria de uma doença que cobria o corpo todo de chagas e que estava quase cega, "não havia remédio que a curasse. Um dia sua irmã [de Sebastião] levou a enferma até a fonte. Lá lavou o corpo e o rosto da doente. Ficou limpinha. Viveu muitos anos. Ainda enxergava bem, quando morreu aos 115 anos" (VERDI, 1987, p. 206). O espaço sagrado tornase assim uma maneira de expressar o sentimento religioso.

Donária Silvia dos Santos, casada com Romário Fraga dos Santos, moradora de Soledade, relatou um milagre atribuído ao monge, que teria feito chover e acabar com a seca que vinha destruindo a plantação da família:

Eu já era casada, isso eu vou contar, assim um causo, um tipo de milagre assim. Então eu disse assim para Romário, eu tinha só o Neri e o Pedro, eu disse assim: - eu vou lá na cruz do Santo Monge, porque ele deixava gravado assim a cruz onde ele passava ele deixa uma cruz, sempre deixava no mato. Dai eu disse assim eu vou lá Romário prá acende umas velas lá pro Santo Monge prá chover. Nós tinha uns, mundo de roça, acho que uns dois ou três alqueires, plantado de milho, de dezembro. Dai fui lá rezar. E a comadre Dorvalina, mãe do Pedro, do compadre Torado, foi comigo dai com as criança. Mas olha eu cheguei lá naquele mato assim tão, tinha pedras assim, mais lá não ía gente, era deserto assim, mas recém, eu acho que recém tinha saído o Santo Monge estava molha- da a pedra, mas só molhada, a seu Bira, assim que tinham botado a água. Não tinha assim nada que ninguém tivesse lá. Dai eu fui e disse prá comadre Dorvalina, minha companheira das crianças, eu disse - ó o Santo Monge saiu agora mesmo daqui. Olha ai a, tá molhada a pedra onde a gente, na beira da cruz onde agente acende as velas (SANTOS, Donária; SANTOS, Romário. Entrevista concedida a Fabian Filatow. Soledade, 02 abril 2000).

Podemos indicar que a figura do monge e o corpus sagrado - rezas, crenças e lugares sagrados - propiciaram reunir uma parcela da comunidade - os Monges Barbudos -, dando uma homogeneidade à fé dos caboclos e, mediante essa união, uma identidade.

Os Monges Barbudos nas fontes policiais

Realizando a interpretação a partir de vestígios e indícios (GINZBURG, 1989), foi necessário dedicarse a uma re-leitura das fontes oficiais. Leitura que uma primeira historiografia percebeu como desconectada ou mesmo secundárias, mas que quando foram intercaladas por novos questionamentos e hipóteses de trabalho mostraram-se de significativa relevância. Neste estudo foram utilizados relatórios policiais e processos crimes produzidos na ação movida pelo Estado contra os Monges Barbudos com o propósito de obter informações sobre seus membros e sua religiosidade.

Antes de analisarmos os documentos, gostaríamos de esclarecer que a nomenclatura Monges Barbudos foi atribuída ao movimento religioso, ou seja, nos documentos policiais foi transcrito a forma como aqueles que se opuseram ao movimento os identificavam, seguidores do santo monge e os homens mantinham a tradição da barba longa, assim Monges Barbudos. Na entrevista concedida à imprensa, o capitão Riograndino da Costa e Silva, que esteve no local do conflito descreveu os membros do movimento desta maneira:

[...] barbas compridas, cabelos grandes, com grande devoção religiosa, naturalmente deturpada, principalmente no cul- 
to a Santa Catarina. Esse sentimento religioso inculcado naquelas pessoas ignorantes [...] aparecem reunidos e agrupados em torno de capelas isoladas, existentes na referida região. (CORREIO DO POVO, Porto Alegre, 27 ABR 1938, p. 14).

Através dos documentos construímos uma interpretação que expressa uma lógica a respeito dos acontecimentos e da nomenclatura Monges Barbudos. Para esse fim, nos utilizamos de fontes policiais, produzidas inicialmente com o objetivo de dar ciência sobre os acontecimentos ocorridos durante a operação militar em Soledade aos seus superiores em Porto Alegre. Nas fontes encontramos referências aos hábitos, costumes e ensinamentos dos Monges Barbudos. De uso dessas informações, realizamos uma análise do tratamento dado aos membros do movimento com o contexto nacional vigente no período.

Interessa-nos aqui a questão semântica, ou seja, os adjetivos e expressões utilizadas para descrever o movimento. Percebemos que se trata de um vocabulário análogo ao utilizado para qualificar grupos relacionados ou possivelmente relacionados com as ideias comunistas, muito presente no Brasil da década de 1930. Além da desqualificação política, identificamos também a desqualificação religiosa, tratando-os como aberrações e fruto do fanatismo, reforçando estereótipos quando da ocorrência destes movimentos ao longo da História do Brasil.

No primeiro relatório identificamos dados significativos para a compreensão do uso da força e a ideia da qual estava imbuída a força militar ao se deslocar ao município de Soledade:

Consoante vossa determinação telegráfica [está se reportando ao Comandante Geral da Brigada], fiz sair daqui, na madrugada do dia 19 do corrente [março de 19387, um contingente composto de vinte praças sob o comando do $2^{\circ}$ tenente Arlindo Rosa, com destino ao $6^{\circ}$ Distrito deste municipio [Soledade] a fim de re- conhecer e dispersar uma reunião de fanáticos que constava existir e que estavam empregando ideias subversivas. (Relatório enviado ao Comandante Geral da Brigada Militar. Soledade, 30 de março de 1938, assinado pelo $1^{\circ}$ Tenente Comandante do Destacamento Januário Dutra, p. 1.)

Dois dados são relevantes: o primeiro o que demonstra a ciência a respeito da existência dos Monges Barbudos antes da data do confronto ocorrido entre os dias 13 e 17 de abril de 1938, ou seja, a movimentação do grupo já era conhecida pelo Comando Geral da Brigada Militar, a tal ponto de ter sido enviado para a localidade um agrupamento militar de reconhecimento. O segundo dado diz respeito ao uso das expressões “reunião de fanáticos e ideias subversivas". Essas definições eram atribuídas aos grupos comunistas ou divergentes do sistema, tanto político quanto religioso. Assim temos uma dupla exclusão, política, por serem inimigos da nação, possíveis comunistas; e religiosa, um grupo que se desviou da fé verdadeira, um fruto da ignorância, fanáticos.

Podemos, assim, interpretar que a força tarefa da Brigada Militar estava preocupada em conter um possível grupo comunista ou, pelo menos, um grupo contrário ao Estado Novo, visto ser uma região conflituosa e de passado divergente frente às determinações do governo.

Recebendo um enquadramento semelhante aos destinados aos "inimigos", temos que o movimento foi identificado como subversivo e gerador de "ideias subversivas", desta forma se enquadrou também como inimigo nacional, uma ameaça à ordem instaurada, e como tal deveria ser combatido.

Corroborando com a ideia de que a Brigada Militar buscava encontrar entre os monges agentes comunistas, temos:

[...] no dia 22 de março, foi remetido pelo tenente Arlino, um grupo de oito 
fanáticos que haviam se apresentado a ele [...]. Interroguei demoradamente cada um deles, verifiquei minuciosamente todos os documentos e demais papéis que possuíam, não tendo encontrado tanto nas declarações como nos papéis nada de importância, que indicasse a pregação de ideias exóticas. (Relatório enviado ao Comandante Geral da Brigada Militar. Soledade, 30 de março de 1938, assinado pelo $1^{\circ}$ Tenente Comandante do Destacamento Januário Dutra, p. 1.)

Através do documento, não se confirmou a ideia de serem comunistas, nada foi encontrado que comprovasse a suspeita, mas isso não foi motivo para que a repressão ao movimento, bem como a negação da sua cultura, fosse evitada.

A explicação apresentada pelo $2^{\circ}$ tenente Arlindo Rosa estava baseada numa visão preconceituosa frente aos nacionais que habitavam a região. Segundo o relatório, a condição de serem caboclos favoreceu o florescimento desses comportamentos tidos como exóticos e de ideias subversivas. Após dez dias de diligência pelo sertão íngreme do sexto distrito, relatou o $2^{\circ}$ tenente:

Como me é dado a observar, a maior parte do pessoal que habitam nos lugares acima mencionados são descendentes do nosso caboclo indolente, pouco gostam de trabalhar, de maneiras que, a miséria começou a bater-lhe a porta da casa, então, por meio de uma seita religiosa tendo como padroeira a Santa Catarina, procuram a se reunirem e se auxiliarem mutuamente. Os mais espertos então começaram a fazer a propaganda da religião, dizendo que, quem não pertencesse aquela religião muito em breve morreria e seus bens seriam repartidos com o pessoal da seita, aconselham também andarem desarmados, respeitar as autoridades, apanharem e não brigarem, não beberem, trabalharem pouco, não trabalharem sábados e nem domingo e purificarem o sangue, tomando Caroba, erva de mato e outras. (Relatório enviado ao Comandante Geral da Brigada Militar. Soledade, 30 de março de 1938, assinado pelo $1^{\mathrm{o}}$ Tenente Comandante do Destacamento Januário Dutra, p. 2 e 3).
Além do desprezo frente ao nacional, o comentário contribui para desprestigiar o movimento, fazendo uso dos termos "fanáticos" e "seita" desmerece sua religião. A "divisão dos bens entre os membros da seita" foi mais um ingrediente para a construção da propaganda de serem inimigos da nação, pois a religião pregaria o fim da propriedade privada, sendo que tudo pertenceria a todos, desde que participantes do movimento. Porém, no final da citação podemos identificar algumas informações referentes aos ensinamentos dos Monges Barbudos, e estes dados se tornam de extrema importância, pois além de nos possibilitar conhecer as instruções pregadas aos membros do movimento, são informações oriundas da versão oficial, não é a voz dos monges, mas sim daqueles que os combateram, é a releitura da fonte oficial. Podemos ler claramente que a religião dos Monges aconselhava a andarem desarmados, o que era significativo numa região violenta e conflitante como Soledade e arredores. $\mathrm{O}$ respeito às autoridades também era defendido. Solicitava a não abusarem de bebida alcoólica, não brigarem, fatos que deveriam ser corriqueiros, pois, do contrário, não haveria a necessidade de serem condenados. Com esses indícios, fica difícil aceitar a ideia que o movimento fosse um grupo violento e fomentador de agitações, que viessem a oferecer alguma ameaça à ordem vigente.

Nos documentos temos ainda informações sobre a imigração em Soledade, que demonstram que a cultura dos monges, dos caboclos que participam do movimento, não foi compreendida. Acreditamos que houve um choque cultural, que atingiu também o religioso, vejamos:

Os colonos de origem estrangeira e os que não querem fazer parte da religião e que habitam naquelas paragens, vendo a união dos monges como são conhecidos e crescerem dia a dia os adeptos, estão ficando alarmados e começam a fazer os mais desencontrados comentários. Conforme estou informado, os fanáticos se 
reúnem sábados e domingos nas igrejas a rezarem completamente desarmados $e$ depois dispersam-se e cada um vai para a suas casas. (Relatório enviado ao Comandante Geral da Brigada Militar. Soledade, 30 de março de 1938, assinado pelo $1^{\mathrm{o}}$ Tenente Comandante do Destacamento Januário Dutra, p. 3.)

O Brasil da década de 1930 era regido por um projeto que se apoiava na promessa do progresso e da modernidade, percebemos no relato o confronto entre o arcaico e o moderno. Isso quer dizer que o nacional foi visto como expressão de "atraso", pois reiteradas vezes os Monges Barbudos foram tidos como "fanáticos" e sua religião qualificada como "seita". Ao longo da história dos movimentos sociorreligiosos no Brasil percebemos estas expressões associadas com atraso, ao ultrapassado, acontecimentos de grupos ignorantes e incultos, enfim, foram apresentados como grupos incapazes de terem cultura. $\mathrm{O}$ mesmo aconteceu com os Monges Barbudos, os quais receberam essa tradição depreciativa.

Justamente contra esse arcaico se ergue o Brasil moderno na luta para excluí-los de sua convivência, divulgando a ideia de que o trabalho enobreceria o homem e modernizaria o país. Neste contexto compreendemos o significado das palavras que declararam que os "nacionais não são dados ao trabalho, é o nosso caboclo indolente". Os estrangeiros foram tidos como semeadores da modernidade. Os europeus trabalhavam e praticavam religiões "normais". O caboclo, por sua vez, assumiu a figura da mistura, da "raça inferior" na qual o fanatismo religioso encontrou solo fértil, sendo fruto da ignorância ou da "esperteza de alguns", chegando ao extremo de se tornarem "fanáticos", oferecendo riscos à ordem vigente.

Temos a menção de que os Monges não portavam armas, apenas se reuniam nos fins de semana nas igrejas para realizarem suas orações e liturgias. O fato extraordinário era a religião dos Monges Barbudos justa- mente por agregar rituais e crenças próprias de sua cultura.

A conclusão do tenente Januário Dutra sobre a origem dos monges é de incerteza: "Sr. Coronel, apesar de não ter encontrado, não posso negar ou afirmar a inexistência de algum núcleo disfarçado, para inocular, aos poucos, ideias exóticas aos moradores da referida região". Mesmo não encontrando nada que relacionasse os Monges Barbudos com o comunismo, ocorreu a instauração da ordem, a repressão.

\section{Processos Crimes como fontes para os Monges Barbudos}

Os acontecimentos ocorridos entre os dias $14 \mathrm{e}$ 17 de abril de 1938, no interior de Soledade, tiveram repercussão na imprensa. Após os conflitos, permaneceram na região alguns efetivos da Brigada Militar com o propósito de evitar o reagrupamento e novas reuniões dos Monges Barbudos. Além desta tarefa o grupo militar presente na localidade estava à procura do líder do grupo, André Ferreira França. Após quatro meses, este acabou sendo localizado e morto na residência de José Crespim da Rosa. Além de Deca França, também morreu Antônio Mariano dos Santos, igualmente identificado pelos militares como membro do movimento religioso.

A repercussão dessas mortes acabou por chamar a atenção do poder judiciário. A Justiça Pública moveu um Processo Crime Sumário, a fim de apurar o contexto e as condições nas quais se sucederam as mortes de André Ferreira França e Antônio Mariano dos Santos, ocorridas na madrugada de 16 de agosto de 1938, na localidade denominada Costa do Rio Lagoão, que na época era o primeiro distrito do município de Sobradinho.

Esse Processo Crime Sumário também buscava averiguar um possível abuso de poder por parte dos po- 
liciais. Foram indiciados militares e civis que participaram da ação de perseguição ao líder religioso, os quais estiveram presentes quando ocorreram as referidas mortes.

Um segundo Processo Crime Sumário, cujos autos também se encontram no Arquivo Público do Estado do Rio Grande do Sul (APERS), foi aberto para averiguar um conflito envolvendo remanescentes dos Monges Barbudos. Esse conflito ocorreu no município de Sobradinho no decorrer de 1938 e foi motivado pela ocorrência de uma reunião não autorizada de pessoas que professavam a religião do movimento.

Nesse mesmo período, estavam sendo investigados e julgados diversos crimes atribuídos ao exgovernador Flores da Cunha. Dentre os assuntos investigados constavam questões dos armamentos que foram enviados para o estado gaúcho na época da Revolução Constitucionalista (1932) e que não teriam sido devolvidos, além de possíveis compras de materiais bélicos efetuados durante o governo de Flores da Cunha. Os jornais da época também estampavam o caso do assassinato do jornalista Waldemar Rippol (cf. RANGEL, 2001). Com a abertura e instauração desses processos, a interventoria buscava demonstrar um novo momento na vida nacional. Além disso, buscava ainda efetuar o julgamento dos possíveis crimes cometidos no período anterior ao Estado Novo.

Acreditamos que também o caso das mortes ocorridas em agosto de 1938 em Soledade, envolvendo pessoas identificadas com os Monges Barbudos, também estariam inseridos nessa perspectiva: a de julgar a ação militar para demonstrar a imparcialidade do novo regime. Salientamos que o processo foi instaurado contra os militares e os civis que colaboraram com a força policial, os quais tiveram participação direta na ação de repressão aos Monges Barbudos, repressão da qual resultou a morte dos principais líderes do movimento e na prisão de alguns dos seus membros; porém, não foi aberto nenhum processo contra os membros do grupo religioso, que foram acusados de comunistas.

Segundo a historiografia pertinente, André Ferreira França teria sido morto no momento em que se entregaria aos policiais que o perseguiam por quatro meses, pois ele estaria cansado de viver escondido. Com a leitura do processo crime, novas informações e versões surgiram

Contra os Monges Barbudos foi instaurada a proibição de manterem suas reuniões religiosas. Foi essa proibição que gerou novos problemas aos moradores daquela região.

Cientes de que o movimento dos Monges Barbudos carece de fontes documentais e de que, dentre as existentes, não se destacam documentos que tenham sido redigidas pelos membros do grupo, não podemos deixar de valorizar os processos crimes.

Das fontes que compõem o corpus documental disponível temos que significativa parcela foi produzida pelos órgãos oficiais responsáveis por reprimir o movimento. Mesmo assim, esses documentos oferecem significativas contribuições para uma análise mais detalhada do movimento e dos motivos alegados pelo Estado a impor a esse uma violenta repressão.

Destacamos igualmente que esses documentos, tanto os policiais quanto os judiciais, foram elaborados no calor da hora, no momento em que reprimiam o movimento ou estavam sob o impacto da ação. Estes, por sua vez, não tinham por objetivo a ampla divulgação nem a intenção de serem expostos publicamente; eram documentos ordinários e internos da vida cotidiana militar, que tinham como função dar ciência aos oficiais sobre os acontecimentos ocorridos em Soledade. Outros objetivaram informar o interventor sobre os acontecimentos, ações, resultados das ações militares postas em 
prática no combate ao grupo de ideias "exóticas" e "subversivas" que "alarmava" a população de Soledade e Sobradinho. Esses documentos associados às demais fontes oferecem alguns fragmentos através dos quais podemos perceber sinais, rastros e vestígios do que teria acontecido, o motivo da repressão e da violência praticada contra os camponeses da região de Soledade. Possibilitam também uma interpretação para além da questão religiosa; não que esta estivesse ausente, muito pelo contrário. Porém, possibilitou novas explicações para a prática da violência. Através do questionamento e análise desse mosaico documental, indicamos significativa presença das questões políticas no caso da repressão imposta aos Monges Barbudos.

Através desses processos, podemos ter acesso às narrativas produzidas pelas testemunhas, os relatos testemunhais tanto de civis quanto de militares que estiveram envolvidos nos acontecimentos. Temos alguns vestígios narrativos daqueles que acusaram e defenderam os envolvidos no crime ocorrido em agosto de 1938, e que às vezes, remeteu-se a momentos anteriores.

Através desses, foi possível acessarmos alguns fragmentos narrativos produzidos a partir dos relatos policiais que estiveram envolvidos na ação direta ou indiretamente. Esses militares depuseram no processo instaurado para averiguar o caso da morte de Deca França. Foram transcritos os depoimentos dos policiais que estiveram presentes nos acontecimentos de agosto de 1938 e também os das autoridades policiais que eram responsáveis pela ação repressora que não estavam presentes no teatro das operações. Na leitura des- sas narrativas, foram sendo resgatados alguns fragmentos de uma história quase esquecida e perdida no tempo. Podemos extrair conteúdos significativos para compreender essa história, não somente através do que está escrito nos autos, mas também nas ausências, nas questões que não foram realizadas, formuladas, esquecidas, naquilo que não foi considerado como relevante e que, consequentemente, deixou de ser investigado ou apurado.

\section{Apontamentos finais}

Os Monges Barbudos ficaram por um longo período submetido ao esquecimento, porém, nas últimas décadas foram retomados estudos que buscaram compreender sua origem, religiosidade e as motivações para a repressão que foi imposta a estes pelo Estado. Neste sentido, nosso estudo buscou ofertar novas fontes, algumas delas inéditas para o estudo do movimento, caso dos processos crimes. A leitura e análise destes documentos permitem identificar uma motivação política para a repressão. Além disso, permitem inserir o movimento religioso nas disputas políticas travadas no decorrer dos anos de 1930 e 1940 . Retomando a leitura das demais fontes, tais como imprensa e documentos eclesiásticos, seguindo os vestígios e os indícios estas fontes corroboraram a presença da disputa política. Assim, acreditamos ter contribuído com a ampliação da divulgação das fontes existentes para a pesquisa sobre os Monges Barbudos, movimento religioso que carece de uma maior historiografia. Almejamos que novos estudos possam surgir. 


\section{Fontes}

Jornal Correio do Povo (abr., dez., 1938)

Jornal Coojornal (Maio, 1980)

Jornal Kolonie, Santa Cruz do Sul, 27 ABR 1938.

RELATÓRIO apresentado ao Comandante Geral da Brigada Militar pelo Major José Rodrigues da Silva, sobre os acontecimentos ocorridos nos municípios de Soledade e Sobradinho, com surto de fanatismo religioso praticado por indivíduos que se tornaram conhecidos por "monges barbudos", 12 de julho de 1938. (APERS - 1939 - Processo Monges Barbudos - Cx. 1 - Est. 9A - 171 G-9)

PROCESSO CRIME. JUSTIÇA PÚBLICA. Processo Crime Sumário contra o cabo Antônio Porto, Praça Lucas Campos Galvão, civis Pedro Simon, José Henrique Simon, Benedito Paulo do Nascimento, Aparício Miranda e João Elberto Oliveira. Volume I e II. Escrivania do Juri de Sobradinho - 1938-1942. (APERS - Processo Crime Município Sobradinho - Cartório Cível e Crime - anos 1929 - 1941. Maço nº 23 - número 167 a 177 - Estante 8)

TRIBUNAL DE APELAÇÃO DO ESTADO DO RIO GRANDE DO SUL. 1941. Segunda Câmara Criminal. $3^{\mathrm{a}}$ Classe. Relator, exmo, Sr. desembargador Elziario Nuñez. Apelação Crime, Sobradinho. Clarismundo de Souza, Fábio Domingos dos Santos, Manoel Furtado e Roberto Vargas da Silva, apelados. (APERS - Município Sobradinho. Processo Crime - Cível e Crime. 1939-1942. Maço 14, n. 1 a 23. Estante 3)

\section{Referências bibliográficas}

CHARTIER, Roger. A História Cultural entre práticas e representações. Rio de Janeiro: Bretand, 1990.

CREMONESE, Dejalma. O Massacre do Fundão: memória, oralidade e resistência. Uma história de perseguição e morte na comunidade dos Monges Barbudos no Centro-Serra do Rio Grande do Sul. Ijuí: Editora Unijuí, 2004.

FACHEL, José Fraga. Monge João Maria, a recusa dos excluídos. Porto Alegre; Florianópolis: Ed. UFSC; Ed. UFRGS, 1995.

FILATOW, Fabian. Do sagrado à heresia: o caso dos Monges Barbudos (1935-1938). Porto Alegre, Dissertação (Mestrado), UFRGS, 2002.

Religião e política: o caso dos Monges Barbudos (Rio Grande do Sul, 1935-1938). Métis: história \& cultura, v. 1. n. 2, jul./dez. 2002. Caxias do Sul: Educs, 2003. p. 53 - 73.

. Política e violência em Soledade - RS (1932-1938). Porto Alegre, Tese (Doutorado), Pontifícia Universidade Católica do Rio Grande do Sul, 2015.

FRANCO, Sérgio da Costa. Soledade na História. Porto Alegre: Corag, 1975.

GINZBURG, Carlo. Mitos, emblemas, sinais: morfologia e história. São Paulo: Companhia das Letras, 1989.

GUERREIRO, Caroline Webber. Vulcão da Serra: violência política em Soledade (RS). Passo Fundo: UPF, 2005.

KOPP, Maria da Glória Lopes. A chave do céu e a porta do inferno: os monges barbudos de Soledade e Sobradinho. Porto Alegre, Dissertação (Mestrado), Pontifícia Universidade Católica do Rio Grande do Sul, 2014.

KUJAWA, Henrique Aniceto. O Movimento dos Monges Barbudos. Passo Fundo, Dissertação (Mestrado em História), UPF, 2000.

Cultura e religiosidade cabocla: Movimento dos Monges Barbudos no Rio Grande do Sul - 1938. Passo Fundo: Ed. UPF, 2001.

PEREIRA, André e WAGNER, Carlos Alberto. Monges barbudo e o massacre do fundão. Porto Alegre: Mercado Aberto, 1981. (Documenta, 9) 
RANGEL, Carlos Roberto da Rosa. Crime e castigo: conflitos políticos no Rio Grande do Sul (1928-1938). Passo Fundo: UPF, 2001.

VERDI, Valdemar Cirilo. Soledade, das sesmarias, dos Monges Barbudos, das pedras preciosas. Não-Me-Toque: Gesa, 1987.

WEDY, Garibaldi Almeida. O pequeno grande mundo de Soledade. Porto Alegre: Palotti, 1996.

Submissão: 22/05/2016

Aceite: $25 / 10 / 2016$ 